\title{
Effect of Plant Growth Regulators and Liquid-Solid Nature of the Media on In-vitro Propagation of Curcuma longa (Turmeric)
}

\author{
D.B.R. Swarnathilaka* and K.A.R. Nilantha
}

\begin{abstract}
Micropropagation of Curcuma longa is important for obtaining large scale disease-free planting materials for year-round cultivation, conservation of germplasm and crop improvement programs. The present study was conducted to study the effect of different hormonal combination and solid liquid nature of the media on successful in-vitro regeneration of explants. The results revealed that Murashige and Skoog (MS) medium supplemented with 4.00 $\mathrm{mg} \mathrm{l}^{-1}$ Benzyl amino purine (BAP) and $0.25 \mathrm{mgl}^{-1}$ Naphthalene acetic acid (NAA) has shown the best performances in multiplication. Culturing in liquid media followed by solid culture media was more effective for shoot growth and multiplication compared to continuous culturing in solid or liquid media during the multiplication cycle.
\end{abstract}

Key words- Curcuma longa, Liquid and solid media, Micropropagation,

\section{INTRODUCTION}

Curcuma longa L. (Turmeric), a herbaceous perennial plant belonging to the family Zingiberaceae, is native of IndoMalayan region. It is grown in India, Pakistan, Malaysia, Thailand, Philippines, Japan, China, Sri Lanka, Africa and Central America. Dried rhizome of Curcuma longa is the source of spice turmeric, with its characteristic yellow color. Turmeric is an indispensable item of daily life and is largely consumed as a condiment. Nasirujjaman et al. (2005) reported that Curcuma longa is also valued as raw materials in pharmaceutical industry due to its medicinal properties.

Plant Tissue Culture Research Station Department of Export Agriculture, Walpita, Sri Lanka

*thilakaswarna@yahoo.com
Curcuma longa is grown in wet and intermediate zones in Sri Lanka as a mono crop and an inter crop under coconut. Major growing areas are Kurunagala, Gampaha, Kalutara, Kandy and Matale districts. Turmeric production of Sri Lanka is negligible compared to India. According to the report written by Chougle et al. (2011), India is the largest producer and exporter of turmeric contributing about 80 percent of world production and 45 percent of trade respectively.

Curcuma Spp is propagated using rhizomes. Rhizomes of Curcuma longa have a dormancy period and they sprout during monsoon only. There is a very high demand for planting materials because large quantity of rhizomes is required for new cultivation due to slow rate of propagation. Shirgurkar et al. (2001) stated that 10-20\% of the total yield should be stored for cultivating subsequent cropping year. Maintenance of a huge quantity of seedrhizomes for annual planting is expensive and labour intensive. Germplasm collections of clonal repositories are also seriously affected by fungal and bacterial diseases. Therefore, the risk of transmittance of diseases from one generation to the next is great. Kuanar et al.(2009) reported that Pseudomonas solancearum (bacterial wilt disease), Fusarium oxysporum and Pythium species (soft/root rot) are transmitted through the rhizome and lead to about $60 \%$ of crop losses to growers. Therefore, the traditional propagation method does not ensure supply of disease-free high-quality planting materials for commercial growers of Curcuma longa. Rapid multiplication of different cultivars of Curcuma longa was 
reported earlier through rhizome bud proliferation as well as through other invitro strategies by different workers (Balachandran et al., 1990; Salvi et al., 2002; NirmalBabu and Minoo, 2003).

The present study is an attempt to find out the effect of different hormonal combinations and solid liquid nature of the media for successful in-vitro regeneration of explants. This is important for obtaining large scale disease-free quality planting materials for year round cultivation, conservation of germplasm and finally for crop improvement programs.

\section{MATERIALS AND METHODS}

Fully cleaned buds were immersed in 70\% of ethanol for 30 seconds and then surface sterilized with $30 \%$ of Clorox solution for 30 minutes and washed 4-5 times in sterile distilled water to remove the traces of the disinfectant. After removing outer layers of the buds, sterilized explants were inoculated into the basal Murashige and Skoog, 1962 (MS) medium under aseptic conditions. All cultures were incubated at $26^{0} \mathrm{C}$ with $16 \mathrm{~h}$ photo period in a growth room.

\section{Standardization of the Growth Regulators for Shoot Multiplication}

Turmeric buds established in basal MS medium for 4-5 weeks were introduced into a basal MS medium fortified with twelve treatments structuring factorial combination with Benzyl amino purine (BAP) $(0,2.0$, 4.0 and $\left.6.0 \mathrm{mg} \mathrm{l}^{-1}\right)$ and Naphthalene acetic acid (NAA) $\left(0.00,0.25\right.$ and $\left.0.50 \mathrm{mg} \mathrm{l}^{-1}\right)$ to evaluate the hormonal combinations on multiplication and shoot growth. All cultures were provided with $16 / 8$ photo period at $26^{\circ} \mathrm{C}$ and the data were recorded on the number of auxiliary buds produced, shoot elongation and number of leaves. Twenty explants were used for one treatment and the experiment was repeated three times.

\section{Comparison of Shoot Initiation in Liquid and Solid Forms of Media}

MS medium was prepared by incorporating selected concentrations of $4.00 \mathrm{mgl}^{-1}$ of BAP and $0.25 \mathrm{mgl}^{-1} \mathrm{NAA}$ in solid form and liquid form (solidifying agent). Healthy invitro established buds were introduced into each media after autoclaving. Cultures were provided $16 / 8$ photo period under the intensity of 3000 Lux from cool white light at $26^{\circ} \mathrm{C}$. Liquid cultures were kept in an orbital shaker for slow agitation (speed 80 rpm). This experiment was repeated twice. Observations were made on the number of axillary buds produced, shoot length and number of leaves.

\section{Data Analysis}

The data were analyzed by ANOVA using SAS 9.2 software. Means were compared by the Least Significant Difference (LSD 0.05).

\section{RESULTS AND DISCUSSION}

\section{Effect of Cytokinin and Auxin on In-vitro Proliferation of Shoots}

The effect of different concentrations of BAP and NAA singly or in combination on shoot proliferation and growth performance are presented in Table 1. Axillary bud enlargement and bud induction were not observed in the media without growth hormone. MS medium devoid of BAP even with the presence of 0.25 or $0.50 \mathrm{mgl}^{-1}$ NAA, failed to stimulate shoot multiplication. The maximum number of shoots (9.37) with mean shoot length of $8.56 \mathrm{~cm}$ were recorded when the explants were incubated in the MS medium supplemented with $4.00 \mathrm{mg} \mathrm{l}^{-1}$ BAP and $0.25 \mathrm{mgl}^{-1} \mathrm{NAA}$ (Figure 1a) though the 
result from this treatment was not significantly different from the medium supplemented with $2.00 \mathrm{mg} \mathrm{l}^{-1}$ BAP and 0.5 mgl $^{-1}$ NAA, which produced 8.87 shoots (Table 1 and Figure 1b). However, the maximum shoot growth $(11.25 \mathrm{~cm})$ was observed with $2.00 \mathrm{mg} \mathrm{l}^{-1} \mathrm{BAP}$ and $0.5 \mathrm{mgl}^{-}$ ${ }^{1} \mathrm{NAA}$. These results indicated that addition of BAP and NAA in combination further promoted the proliferation of shoots compared to the growth regulators applied individually. Similar results were reported by Kambaska et al. (2010) who stated that the explants cultured on MS basal medium supplemented with $2.0 \mathrm{mgl}^{-1} \mathrm{BAP}$ and 0.5 $\mathrm{mgl}^{-1}$ NAA showed highest rate of shoot multiplication.

When BAP concentration was increased from 0 to $6.00 \mathrm{mgl}^{-1}$, the highest rate of multiplication (9.37 shoots) was obtained at $4.00 \mathrm{mg} \mathrm{l}^{-1} \mathrm{BAP}$ and $0.50 \mathrm{mgl}^{-1}$
NAA whereas an inhibitory effect was observed at $6.00 \mathrm{mg} \mathrm{l}^{-1}$ BAP either with 0.25 or $0.50 \mathrm{mgl}^{-1}$ NAA ( Table 1 and Figure 2a). Our result was closely related with Nasirujjaman et al. (2005) who reported that best multiplication rates of turmeric in the medium incorporated with $4.0 \mathrm{mgl}^{-1}$ and $0.5 \mathrm{mgl}^{-1} \mathrm{NAA}$. Sunitibala et al. (2001) reported the optimum clonal propagation of turmeric by rhizome bud culture in MS media as $2.00 \mathrm{mg} \mathrm{l}^{-1} \mathrm{BAP}$ and $1.0 \mathrm{mgl}^{-1} \mathrm{NAA}$. Results of our study are in agreement with the observations of Bharalee et al. (2005) who reported that maximum shoot multiplication of Curcuma caesia in MS medium supplemented with $4.0 \mathrm{mgl}^{-1} \mathrm{BAP}$ and $0.25 \mathrm{mgl}^{-1} \mathrm{NAA}$. Dipti et al. (2005) stated that the highest number of multiple shoots in rhizome bud of turmeric was cultured in MS medium supplemented with $3 \mathrm{mgl}^{-1}$ BAP.

Table 1. Bud formation of Turmeric ex-plants on MS media supplemented with different concentration of BAP and NAA

\begin{tabular}{cccll}
\hline $\begin{array}{c}\text { Concentration of } \\
\text { NAA }\left(\mathrm{mgl}^{-1}\right)\end{array}$ & $\begin{array}{c}\text { Concentration of BAP } \\
\left(\mathrm{mgl}^{-1}\right)\end{array}$ & $\begin{array}{c}\text { No of } \\
\text { Shoot Buds }\end{array}$ & $\begin{array}{c}\text { Shoot } \\
\text { Length }(\mathrm{cm})\end{array}$ & $\begin{array}{c}\text { No of } \\
\text { Leaves }\end{array}$ \\
\hline 0.00 & 0.00 & $1.125 \mathrm{f}$ & $5.687 \mathrm{~h}$ & $4.125 \mathrm{f}$ \\
0.00 & 2.00 & $3.250 \mathrm{e}$ & $7.000 \mathrm{fg}$ & $4.875 \mathrm{e}$ \\
0.00 & 4.00 & $3.750 \mathrm{e}$ & $8.437 \mathrm{cde}$ & $4.875 \mathrm{e}$ \\
0.00 & 6.00 & $5.625 \mathrm{~d}$ & $9.125 \mathrm{bc}$ & $4.875 \mathrm{e}$ \\
0.25 & 0.00 & $1.626 \mathrm{f}$ & $6.375 \mathrm{gh}$ & $4.875 \mathrm{e}$ \\
0.25 & 2.00 & $6.625 \mathrm{c}$ & $9.937 \mathrm{~b}$ & $5.375 \mathrm{ed}$ \\
0.25 & 4.00 & $9.375 \mathrm{a}$ & $8.562 \mathrm{cde}$ & $5.500 \mathrm{cde}$ \\
0.25 & 6.00 & $6.750 \mathrm{c}$ & $8.912 \mathrm{bcd}$ & $5.625 \mathrm{bcd}$ \\
0.50 & 0.00 & $1.375 \mathrm{f}$ & $9.000 \mathrm{bc}$ & $6.125 \mathrm{abc}$ \\
0.50 & 2.00 & $8.875 \mathrm{ab}$ & $11.250 \mathrm{a}$ & $6.500 \mathrm{a}$ \\
0.50 & 4.00 & $8.375 \mathrm{~b}$ & $7.812 \mathrm{def}$ & $6.25 \mathrm{ab}$ \\
0.50 & 6.00 & $6.625 \mathrm{c}$ & $7.750 \mathrm{ef}$ & $5.375 \mathrm{de}$ \\
\hline
\end{tabular}

Means followed by the same letter (s) are not significantly different at $p<0.05$ 


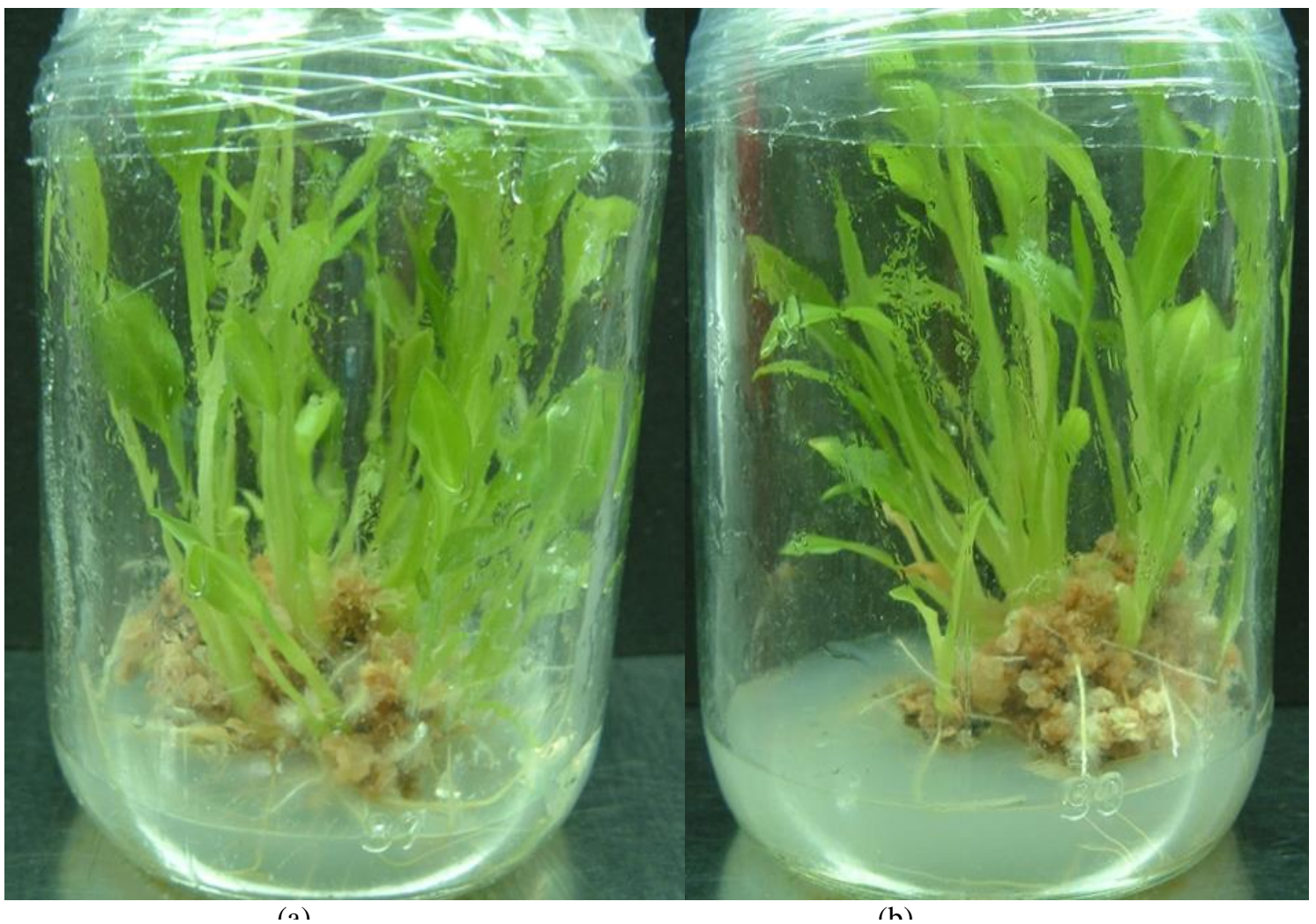

Figure 1. Multiplication of turmeric in MS medium supplemented with hormones (a) $4.0 \mathrm{mgl}^{-1} \mathrm{BAP}$ and $0.25 \mathrm{mgl}^{-1} \mathrm{NAA}$, (b) $2.0 \mathrm{mgl}^{-1} \mathrm{BAP}$ and $0.50 \mathrm{mgl}^{-1} \mathrm{NAA}$.

Cline et al. (1997) explained that enhancement of axillary shoot proliferation in explants cultured on MS medium supplemented with BAP may be due to the role of cytokinin which can overcome the apical dominance.

Analysis of variance showed that the significant interaction between BAP and NAA for number of shoots and length of shoots (Table 1, Figure 2). The highest shoot length was observed on MS media containing $2.00 \mathrm{mg} \mathrm{l}^{-1} \mathrm{BAP}$ in combination with $0.50 \mathrm{mgl}^{-1} \mathrm{NAA}$. It was significantly evident that BAP concentrations beyond 4.0 $\mathrm{mgl}^{-1}$ has decreased the shoot growth (Table 1). This finding is in accordance with $\mathrm{Naz}$ et al. (2009) who reported that the higher concentration of BAP such as $6 \mathrm{mg} \mathrm{\textrm {L } ^ { - 1 }}$ decreases the shoot multiplication rate in turmeric. Rout et al. (1997) also have shown decrease of shoot multiplication of ginger with the increasing dosage of BAP from 6.0 to $8.0 \mathrm{mg} \mathrm{L}^{-1}$.

In this study, a comparison was made in terms of shoot multiplication and plant growth response of turmeric after 12 weeks of culturing in liquid- liquid, solid solid, liquid -solid and solid- liquid phases of the media. Differences in growth rates were observed and the plantlets cultured continuously on liquid or liquid-solid media showed much better shoot induction and shoot growth than those of solid media (Table 2 and Figure 3 (a) and (b). 


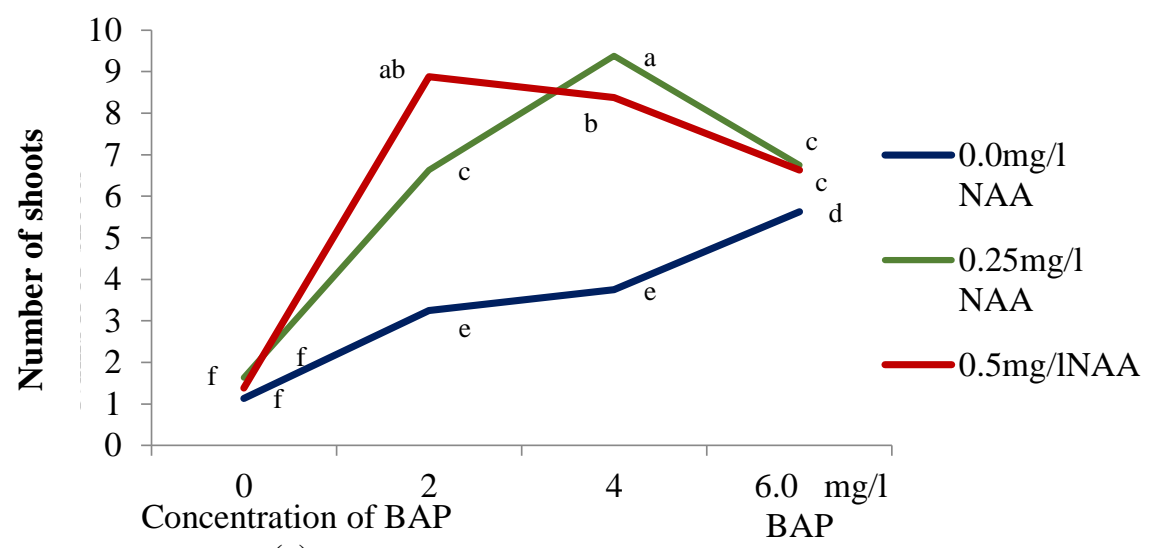

(a)

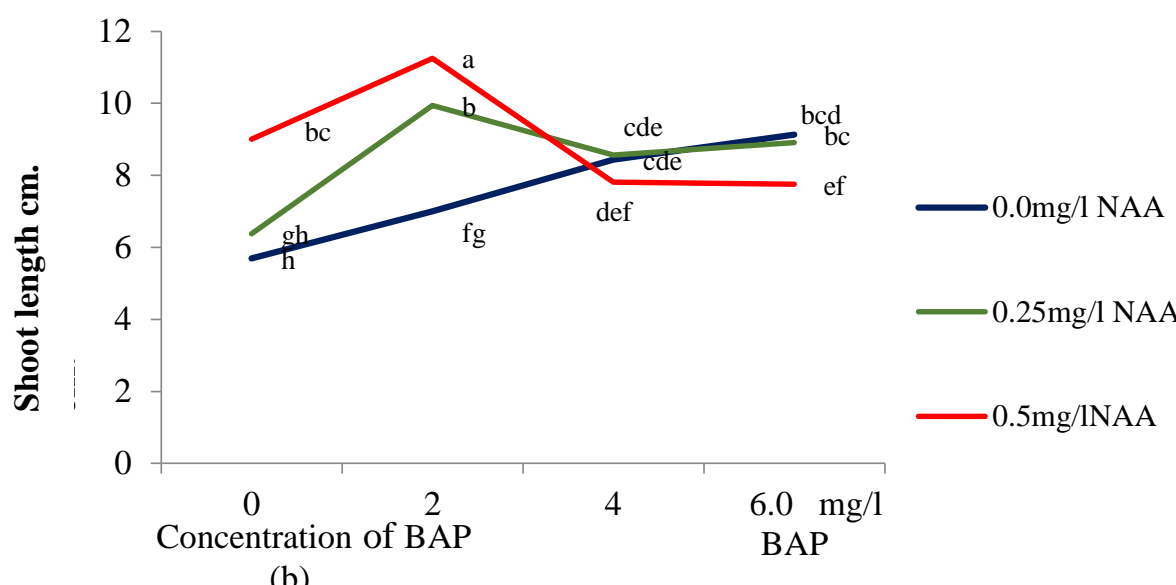

Means followed by the same letter (s) are not significantly different at $p<0.05$

Figure 2. Interaction between BAP and NAA (a) on shoot multiplication (b) Shoot elongation after 6 weeks of culture.

\section{Comparative Study of the Rate of Multiplication in Solid and Liquid Forms of Media}

Table 2. Growth parameters of Curcuma longa in four subculture phases

\begin{tabular}{llll}
\hline Sub culture phase & Number of Shoots & Shoot length $(\mathrm{cm})$. & Number of leaves \\
\hline Liquid-liquid & $17.833 \pm 1.030^{\mathrm{b}}$ & $9.458 \pm 0.811^{\mathrm{a}}$ & $15.5 \pm 2.195^{\mathrm{ab}}$ \\
Liquid-Solid & $20.500 \pm 1.382^{\mathrm{a}}$ & $9.792 \pm 0.542^{\mathrm{a}}$ & $16.583 \pm 1.443^{\mathrm{a}}$ \\
Solid-Liquid & $17.417 \pm 1.311^{\mathrm{c}}$ & $8.542 \pm 0.838^{\mathrm{b}}$ & $14.083 \pm 1.240^{\mathrm{b}}$ \\
Sold-solid & $16.167 \pm 1.193^{\mathrm{c}}$ & $7.792 \pm 0.988^{\mathrm{b}}$ & $14.666 \pm 0.985^{\mathrm{b}}$ \\
\hline
\end{tabular}

Means followed by the same letter (s) are not significantly different at $p<0.05$ 


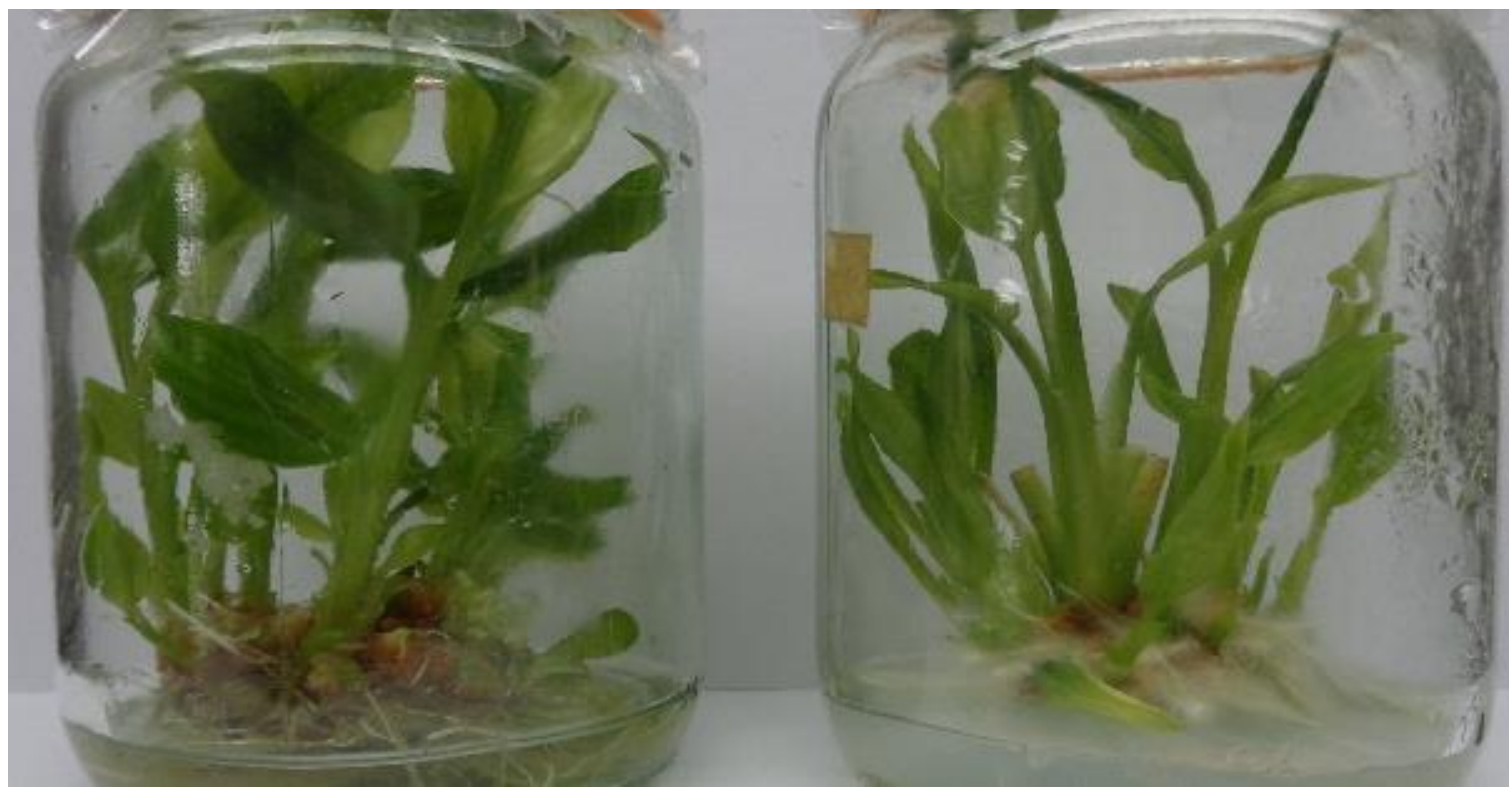

(a)

(b)

Figure 3. Multiple shoot formation in MS media (a) liquid -liquid phase (b) solid-solid phase

There were no significant differences observed in shoot elongation of turmeric between Liquid-Liquid and Liquid-Solid media. The maximum number of shoots (20.50) and shoot length $(9.792 \mathrm{~cm})$ were observed in liquid-solid medium. The plantlets cultured on continuous liquidliquid and liquid-solid showed higher rates of multiplication which were significantly different from the treatments of solid-liquid and solid-solid. There was no significant difference observed in mean shoot length of the multiplied shoots in the treatments of liquid-liquid and liquid -solid while higher mean shoot length and healthy shoot growth with more number of leaves (Table 2) were observed in liquid-solid culture phases. Turmeric cultures in continuous solid media for 12 weeks have shown the lowest performances in multiplication and growth. Our results go in line with Kuria et al. (2008) who reported that lower rate of development of plantlets in solid media compared to liquid media and it was attributed to lower uptake of nutrients in solid cultures. Vyas et al. (2008) also have reported that the plantlets of Chlorophytum borivilianum grown in liquid media showed higher rate of multiplication and growth compared to solid media. Similarly, the direct contact of plantlets with the liquid phase of the medium, contents causes ease in availability of nutrients resulting in better plantlet growth as compared to solid media where nutrient uptake is comparatively difficult due to solidification of the medium. According to the present investigation liquid-liquid and liquid-solid media were found to be superior to solidsolid medium in multiplication and growth of turmeric. The better aeration of cultures in the liquid medium might have been beneficial for shoot formation. Mehrotra et al. (2007) also have reported that the liquid media facilitate closer contact of the shoot base of the plantlets with the nutrient media. In addition, liquid media was cheaper than the solid media. 
However, Mohanty et al. (2008) who reported that the multiplication rate remained same in both liquid and solid media have shown results in contrast to our findings.

\section{CONCLUSION}

The optimum medium to produce multiple shoots was Murashige and Skoog medium supplemented with $4.00 \mathrm{mgl}^{-1}$ Benzyl amino purine (BAP) and $0.25 \mathrm{mg} \mathrm{l}^{-1}$ Naphthalene acetic acid (NAA) while for the shoot elongation, the best medium was medium supplemented with $2.00 \mathrm{mg} \mathrm{l}^{-1}$ BAP and $0.5 \mathrm{mgl}^{-1} \mathrm{NAA}$. Compared to the continuous culturing in solidified medium, shoot number and shoot culturing length were significantly increased by doublephase medium which refers to liquid-liquid or liquid - solid.

\section{ACKNOWLEDGEMENT}

The financial assistance and all facilities received from Department of Export Agriculture in Sri Lanka are gratefully acknowledged.

\section{REFERENCES}

Balachandran, S. M., Bhat, S. R. and Chandel, K. P. S. (1990). In- vitro clonal multiplication of turmeric (Curcuma spp.) and ginger (Zingiber officinale Rosc). Plant Cell Report, 8: 521-524.

Bharalee, R., Das, A. and Kalita, M.C. (2005). In-vitro clonal propagation of Curcuma caesia Roxb. and Curcuma zedoaria Rosc. from rhizome bud explants. Journal of Plant Biochemistry and Biotechnology, 14: 61-63.
Cline, M., Wessel T, Iwamura H (1997). Cytokinin/Auxin control of apical dominance in Ipomoea nil. Plant Cell Physiology, 38:659-667.

Chougle, P.S., Hegde, R.V.,Mokashi, A.N, Vengopal,C.K. and Bhat,R. (2011). Microrhizome production in turmeric (Curcuma longa L.) Karnataka. Journal of Agricultural Science, 24 (4): (493496)

Dipti, T., Ghorade, R.B., Swati, M., Pawar, B.V.and Ekta, S. (2005). Rapid multiplication of turmeric by micropopagation. Annual plant Physiology, 19: 35 - 37.

Kambaska, K., Debashrita, P. and Santilata, S. (2010).Effect of Plant Growth Regulator on In- vitro multiplication of Turmeric (Curcuma longa L. cv.Ranga ). International Journal of Biological Technology, 1(1):1623.

Kuanar, A., Mohanty, S., Panda, M. K. and Nayak, S. (2009). Essential oils from leaves of micropropagated turmeric. Current Science. 96(9):1166-1167.

Kuria, P., Nyende A and Kahangi E, 2008. Cassava starch as an alternative cheap gelling agent for the in vitro micro-propagation of potato (Solanum tuberosum L.). African Journal of Biotechnology, 7(3): 301-307.

Mehrotra, S., Goel, M.K., Kukreja,A.K. and Mishara,B.M.(2007). Efficiency of liquid culture systems over conventional micropropagation: A Progress towards commercialization, African Journal of Biotechnology, 6:1484. Mohanty, S., Panda, M.K., Subudhi, E., Acharya, L. and Nayak, S. (2008). Genetic stability of 
micropropagated ginger derived from axillary bud through cyto photometric and RAPD analysis. Naturforsch, 63c: 747-75

Murashige, T. and Skoog, F. (1962). A revised medium for rapid growth and bioassay with tobacco tissue culture. Physiologia Plantarum, 15: 473-497.

Nasirujjaman, K., M. Salah-Uddin, S. Zaman and M.A. Reza. (2005). Micropropagation of turmeric (Curcuma longa Linn.) through in- vitro rhizome bud culture. Journal of Biological Sciences, 5(4): 490-492.

Naz, S., S. Ilyas, S. Javad and Ali, A. (2009). In vitro clonal multiplication and acclimatization of different varieties of turmeric (Curcuma longaL.). Pakistan Journal of Biotechnology. 41: 2807-2816

Nirmal, Babu, K. and Minoo, D. (2003). Commercial micropropagation of spices. In: Ramesh Chandra and Maneesh Misra, eds. Micropropagation of horticultural crops. Lucknow: International Book Distributing Company, p. 345.

Rout, G.R., S.K. Palai and Das, P. (1997). In vitro micropropagation of ginger (Zingiber officinale Rosc.) interaction of growth regulators and culture conditions. Indian Journal of Herb Spices.

Salvi, N. D., George, L. and Eapen, S. (2002). Micropropagation and field evaluation of micropropagated plants of turmeric. Plant Cell Tissue and Organ Culture, 68(2): 143-151.

Shirgurkar, M. V., John, C. K. and Nadgauda, Rajani, S. (2001).
Factors affecting in-vitro microrhizome production in turmeric. Plant Cell, Tissue and Organ Culture, 64: 511.

Sunitibala, H., Damayanti, M. and Sharma, G. L. (2001). In- vitro propagation and rhizome formation in Curcuma longa Linn. Cytobios.105: 71-82.

Vyas,S.,Rao, M.S., Suthar, R.K. and Purohit, S.D., (2008). Liquid culture systems stimulate in-vitro growth and shoot multiplication in four medicinally important plants. Medicinal and Aromatic Plant Science and Biotechnology. 2(2):96-10 